\title{
High-Strength and High-Speed Bonding Technology using Thick Al-Ni Wire
}

\author{
Jin Onuki, Takao Komiyama, Yasunori Chonan and Masahiro Koizumi* \\ Department of Electronics and Information Systems, Faculty of Systems Science and Technology, \\ Akita Prefectural University, Honjo 015-0055, Japan
}

\begin{abstract}
In order to create high-strength and high-speed thick $\mathrm{Al}$ wire bonding technology, high-temperature bonding at $423 \mathrm{~K}$ using $\mathrm{Al}-\mathrm{Ni}$ wire has been investigated. It was found that Al-Ni wire bonds exhibit higher bonding strength than those of Al wire bonds. Al-Ni wire bonds joined at $423 \mathrm{~K}$ for $40 \mathrm{~ms}$ exhibited high-strength comparable to those of Al-Ni wire bonds joined at RT for $180 \mathrm{~ms}$. It was found that hightemperature, high-speed bonding substantially reduces the occurrence of Si damage. High-temperature and high-speed bonding with Al-Ni wire can be considered as a promising bonding technology for the mass production of low cost power modules.
\end{abstract}

(Received June 4, 2002; Accepted July 10, 2002)

Keywords: thick aluminum wire bonding, aluminum-nickel wire, high temperature bonding, high speed bonding, shear strength, silicon chip damage

\section{Introduction}

Ultrasonic thick Al wire bonding technologies are widely used for the production of power metal oxide semiconductor field-effect transistors (Power MOSFET's) and insulated gate bipolar transistors (IGBT's) which are power devices used in the control systems of auto mobiles and traction motor drives. ${ }^{1-3)}$ In order to achieve high current MOS type power devices, highly reliable modules on which many chips are assembled in parallel must be developed. ${ }^{4,5)}$ For example, in the IGBT module shown in Fig. 1, the Al electrodes on the chips are connected to the common electrodes by thick $\mathrm{Al}$ wire bonding technology. ${ }^{6)}$ The number of $\mathrm{Al}$ wire bonds has to increase as the current required for the module becomes greater. This is to distribute the high current uniformly among the wires.

The reliability of the Al wire bonds depends on the bonding strength between the $\mathrm{Al}$ electrodes on the chip and the $\mathrm{Al}$ wire. The bonding strength increases as the ultrasonic power and bonding time increases. ${ }^{7,8)}$ However, a long application of high ultrasonic power during bonding is likely to induce $\mathrm{Si}$ damage $^{9)}$ and Si damage in a single chip destroys the entire

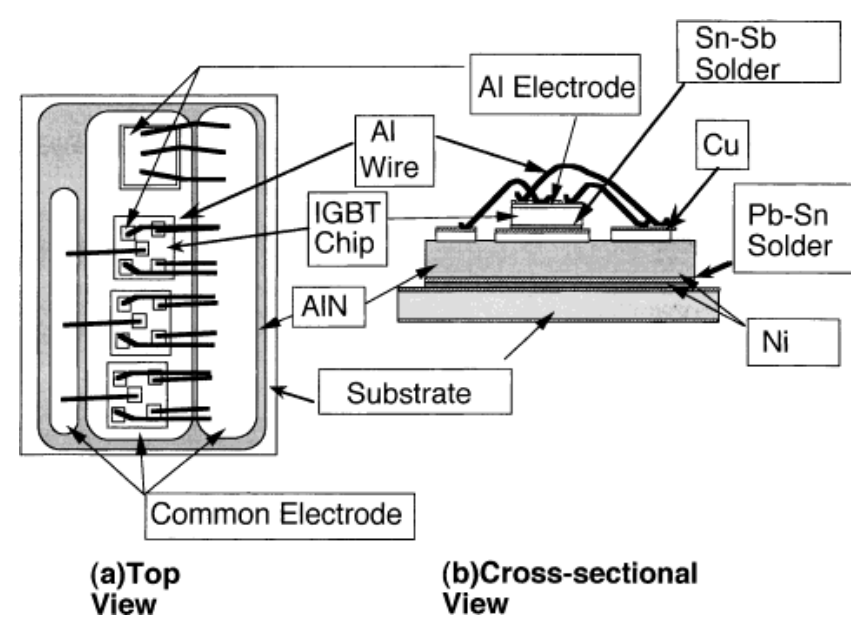

Fig. 1 Schematic illustration of (a) a plane view and(b) a cross-sectional view of an IGBT module. module.

Hence, both the enhancement of the bonding strength and the prevention of $\mathrm{Si}$ damage during the thick Al wire ultrasonic bonding process are considered to be indispensable in the production of a highly reliable module.

Alternately, the deformation of both $\mathrm{Al}$ electrodes and $\mathrm{Al}$ wire during bonding enhances the bonding strength by increasing the true bonded area between them. ${ }^{10)}$ This indicates that $\mathrm{Al}$ alloy wire with greater hardness than pure $\mathrm{Al}$ wire may exhibit higher strength bonding to Al electrodes.

In addition, $\mathrm{Al}$ alloy wire with high corrosion resistance ${ }^{11)}$ is also favorable, because if the water is introduced, it could dissolve ions in the plastic packaged modules and cause corrosion. ${ }^{12)}$ From this point of view, Al-Ni wires, which exhibit higher hardness and corrosion resistance than pure $\mathrm{Al}$, have recently been investigated.

In the previous paper, we reported that high strength bonding could be feasible even in a low ultrasonic power range when the ultrasonic Al wire bonding was done to Al electrodes heated at $423 \mathrm{~K}^{13)}$ This high-temperature bonding also substantially reduced the Si damage.

Furthermore, high-speed bonding technology without $\mathrm{Si}$ damage is also very important for high power modules, where a large number of $\mathrm{Al}$ wires must be bonded and the bonding time reflects greatly on the production cost.

The purpose of this study is to clarify how much we can shorten the bonding time without degrading the bonding strength of the wire bonds or causing a breakdown in module voltage.

\section{Experimental Procedure}

4N Al and Al-50 ppmNi alloy wires with $500 \mu \mathrm{m}$ diameter were used for bonding. Al-50 ppmNi alloy wires were made through three separate processes, vacuum melting at $1073 \mathrm{~K}$; rapid cooling $\left(\fallingdotseq 10^{3} \mathrm{~K} / \mathrm{s}\right)$ in the cast; and cold drawing. It is reported that rapid quenching $\left(10^{5}-10^{8} \mathrm{~K} / \mathrm{s}\right)$ from the melt of an $\mathrm{Al}$ rich-Ni alloy extend the solubility limit of $\mathrm{Ni}$ in $\mathrm{Al}$ from 0.22 mass $\% \mathrm{Ni}$ to 15.4 mass $\% \mathrm{Ni}^{14}{ }^{14}$ We believe that $50 \mathrm{ppmNi}$ are dissolved in $\mathrm{Al}$ matrix. We have confirmed that there were 
no precipitates in Al matrix using optical-microscope with a magnification of 400. The high temperature bonding ${ }^{13)}$ was conducted as shown in Fig. 2. First, bonding substrates were heated to $423 \mathrm{~K}$ by a heater installed in the bonding stage. The surface temperature of the sample was monitored by a thermocouple thermometer.

Then, $\mathrm{Al}$ and $\mathrm{Al}-\mathrm{Ni}$ wires were bonded to $\mathrm{Al}$ electrodes for varying bonding times. The ultrasonic power and load were fixed as $8 \mathrm{~W}$ and $14.5 \mathrm{~N}$, respectively. The hardness of the $\mathrm{Al}$ wire is about $20 \mathrm{Hv}$ and that of $\mathrm{Al}-\mathrm{Ni}$ wire is $23.6 \mathrm{Hv}$.

Figure 3 shows an example of Al-Ni wire bonds joined at $423 \mathrm{~K}$ with $8 \mathrm{~W}$ power and $10 \mathrm{~ms}$ bonding time. Figure 4

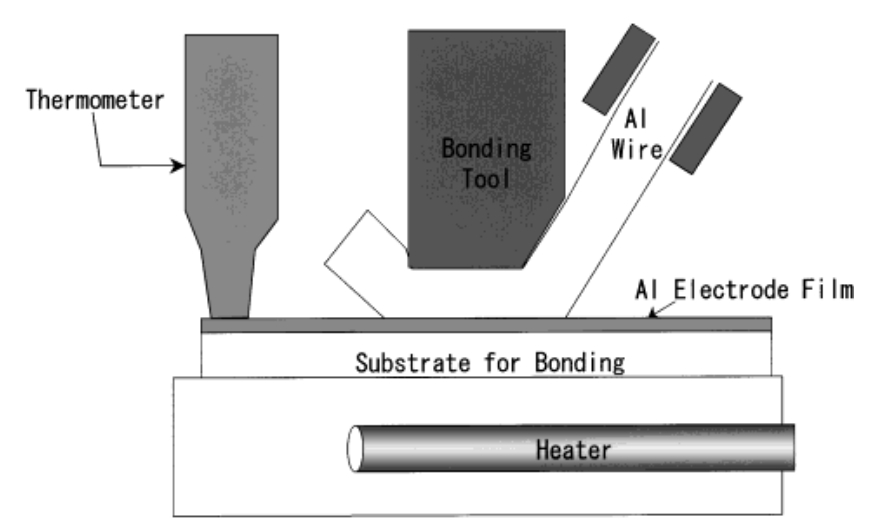

Fig. 2 Schematic illustration of an equipment for high temperature bonding.

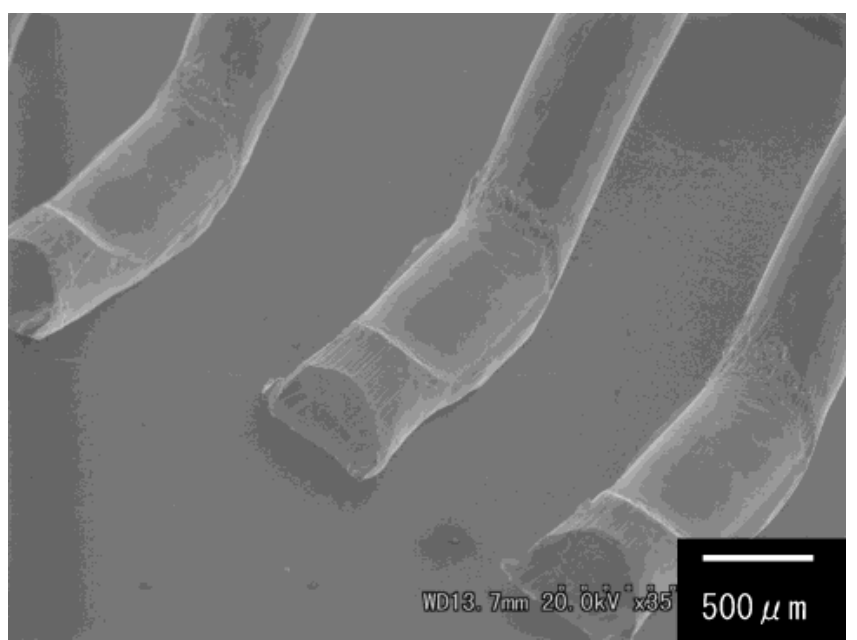

Fig. 3 An example of Al-Ni wire bonds joined at $423 \mathrm{~K}$.

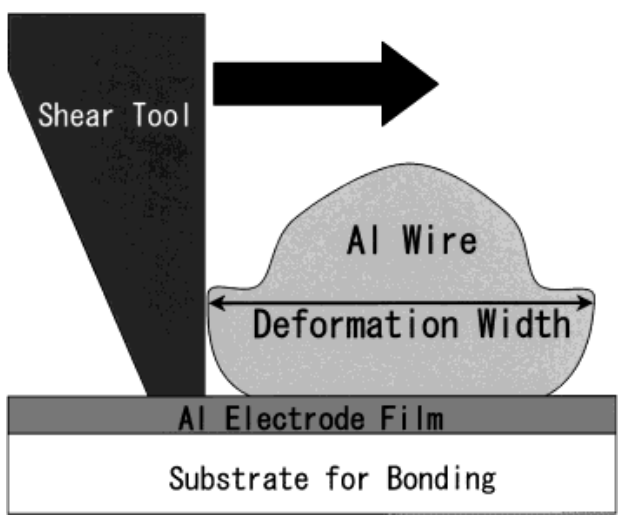

Fig. 4 Schematic illustration of the shear test. shows a shear test of the Al wire bonds using the THINKMTS550 to evaluate bonding strength. After the shear test, fractured surfaces were examined by using scanning electron microscopy (SEM).

In order to determine the Si damage which occurred in the modules, we used a $I-V$ curve tracer. Because, a breakdown at low voltage (less than $100 \mathrm{~V}$ ) is observed when Si damage occurs in the module.

\section{Results and Discussion}

\subsection{The strength of $\mathrm{Al}$ and $\mathrm{Al}-\mathrm{Ni}$ wire bonds joined at RT}

Figure 5 shows the relationship between the bonding time and the deformation width (see Fig. 4) of Al and Al-Ni wire bonds. The deformation width increases with the bonding time for both cases. However, the bonding time necessary to obtain the same deformation width for $\mathrm{Al}-\mathrm{Ni}$ wire is longer by $40 \mathrm{~ms}$ than that for $\mathrm{Al}$ wire. This is due to the fact that the hardness of Al-Ni wire is higher than that of $\mathrm{Al}$.

The shear strength of the bonds for $\mathrm{Al}$ and $\mathrm{Al}-\mathrm{Ni}$ wires is plotted against their bonding time in Fig. 6. The shear strength for both $\mathrm{Al}$ and $\mathrm{Al}-\mathrm{Ni}$ wires increases with bonding time. It is found that the shear strength of the Al-Ni wire bonds is higher by about $5 \mathrm{~N}$ than those of the $\mathrm{Al}$ when comparing them using the same bonding time. The results of Figs. 5 and 6 suggest that the strength of $\mathrm{Al}-\mathrm{Ni}$ wire bonds is higher than that of $\mathrm{Al}$ wire bonds when comparing them with the deformation width. Hence the shear strength of Al and $\mathrm{Al}-\mathrm{Ni}$ wires are plotted against the deformation width in Fig. 7. The shear strength increases with deformation width in both cases. However, the shear strength of Al-Ni wire bonds is about $7 \mathrm{~N}$ higher than that of the $\mathrm{Al}$ wire when compared with the same deformation width. Furthermore, the deformation width of $\mathrm{Al}-\mathrm{Ni}$ wire bonds corresponding to the same shear strength of $\mathrm{Al}$ wire bonds is $30 \mu \mathrm{m}$ smaller than that of Al wire bonds.

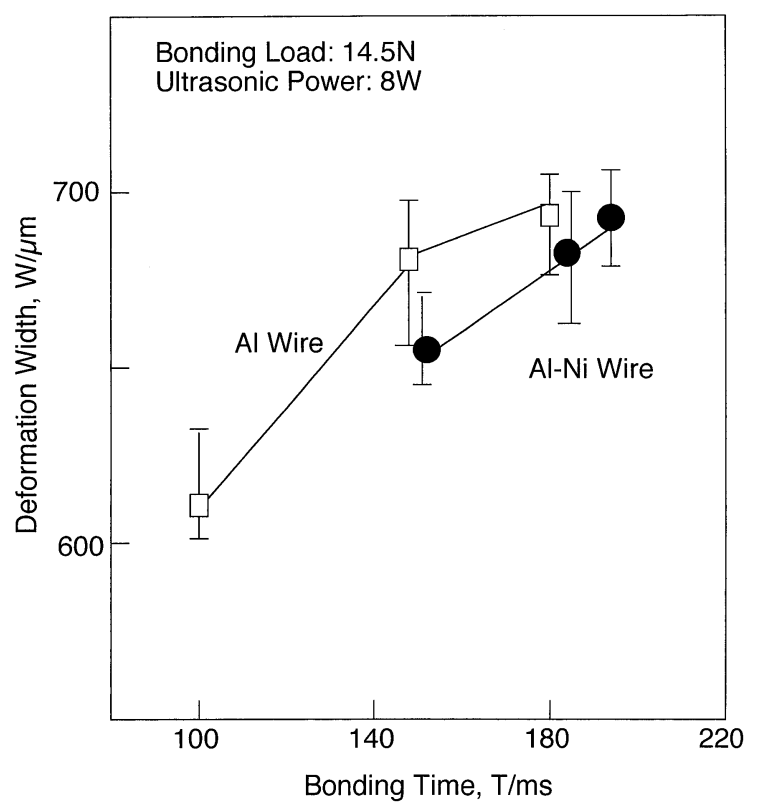

Fig. 5 Relationship between the bonding time and the deformation width of $\mathrm{Al}$ and $\mathrm{Al}-\mathrm{Ni}$ wire bonds. 


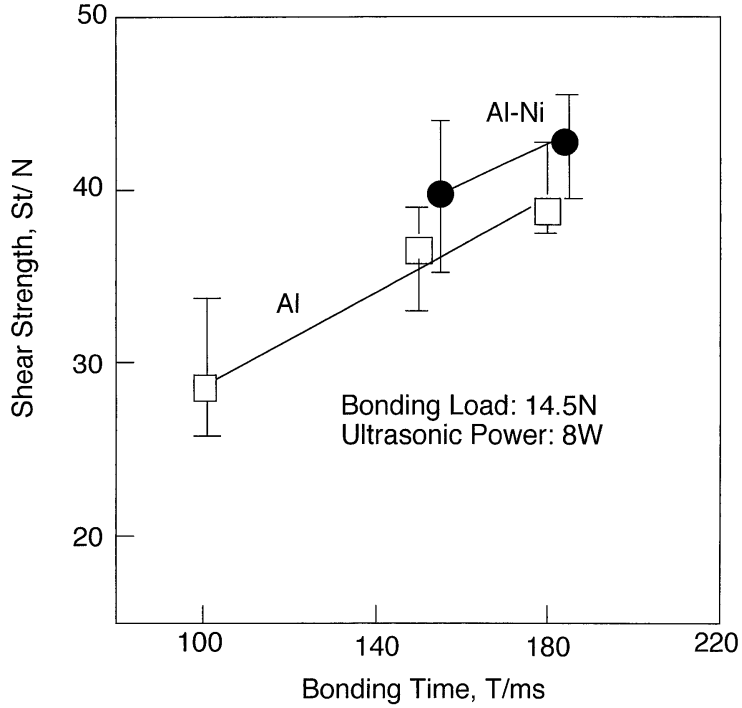

Fig. 6 The shear strength for $\mathrm{Al}$ and $\mathrm{Al}-\mathrm{Ni}$ wire bonds as a function of bonding time.

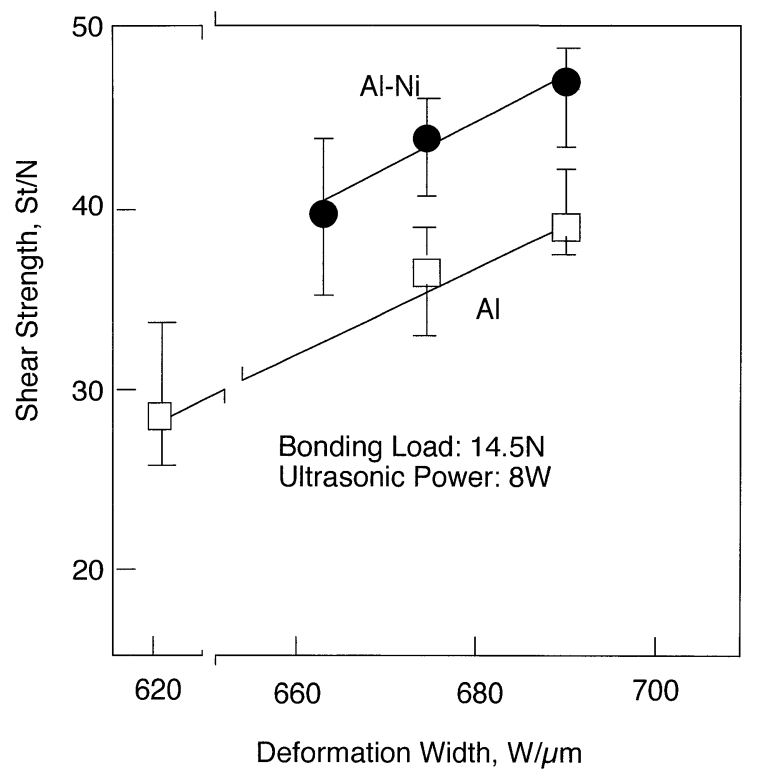

Fig. 7 Shear strength as a function of deformation width for $\mathrm{Al}$ and $\mathrm{Al}-\mathrm{Ni}$ wire bonds.

According to the data obtained for the Al ball bonding process, ${ }^{15)}$ the true bonded area between $\mathrm{Al}$ balls and $\mathrm{Al}$ electrodes increases with the ball hardness, and hence the bonding strength increases with the ball hardness. Therefore, the result of Fig. 7 can be interpreted as follows: A hard Al$\mathrm{Ni}$ wire results in sufficient deformation of the $\mathrm{Al}$ electrodes to rupture the oxide film, giving a larger true bonded area, and hence a stronger bond, even if the deformation width is small. ${ }^{15)}$ In consideration of the above facts, it can be said that wires harder than pure Al, including Al-Ni alloy, enhance the bonding strength.

\subsection{Investigation of Si damage}

The breakdown voltages of modules bonded with $\mathrm{Al}$ and Al-Ni wires by the varying bonding time were evaluated using curve tracer. The breakdown voltage for a module without Si damage was $2000 \mathrm{~V}$, and for one with Si damage occurring during the bonding process was less than $100 \mathrm{~V}$.

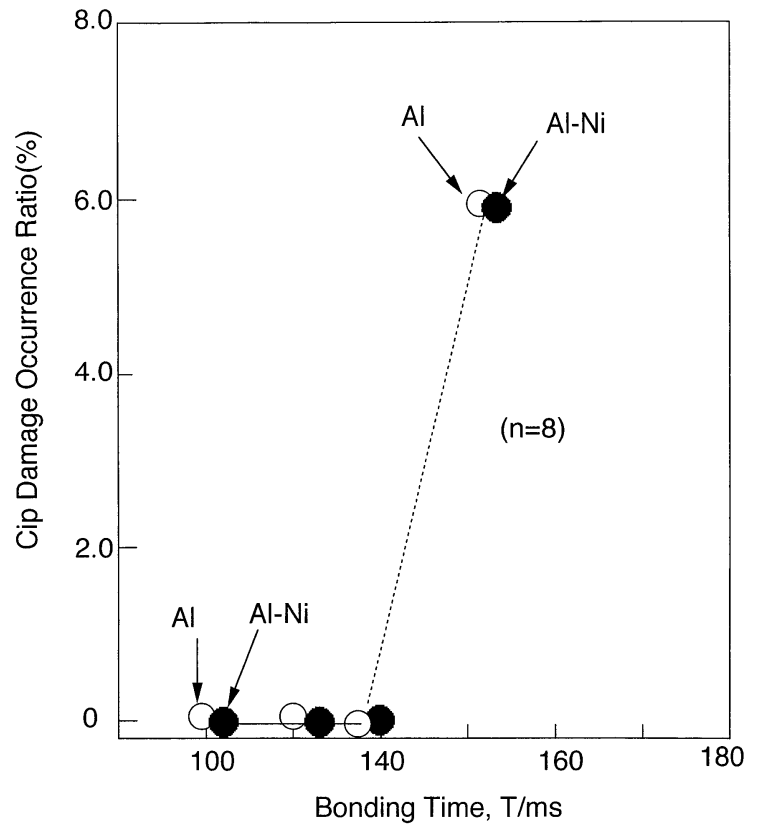

Fig. 8 Si chip damage occurrence ratio as a function of bonding time.

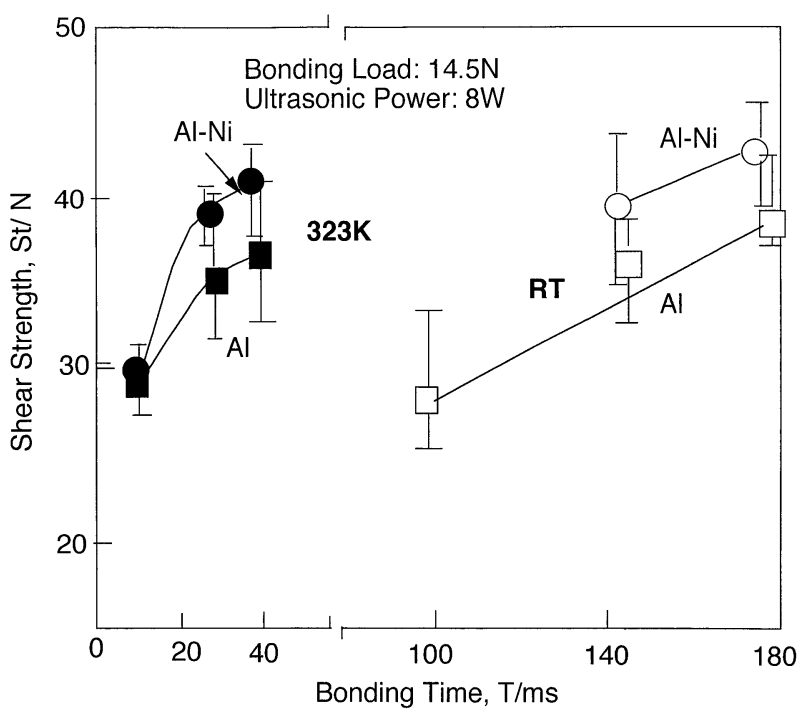

Fig. 9 The shear strength of $\mathrm{Al}$ and $\mathrm{Al}-\mathrm{Ni}$ wire bonds as a function of bonding time.

Figure 8 shows the Si chip damage occurrence ratio for both modules bonded with $\mathrm{Al}$ and $\mathrm{Al}-\mathrm{Ni}$ wire as a function of the bonding time at RT. In both cases, Si chip damage does not occur when the bonding time is less than $140 \mathrm{~ms}$. While, Si chip damage occurs when the bonding time becomes longer than $140 \mathrm{~ms}$.

\subsection{Effect of high temperature bonding on bonding time}

Based on the results dealing with the relationship between Si damage and bonding time, the bonding time should be less than $140 \mathrm{~ms}$. In a previous report, we confirmed that the shear strength by high temperature bonding at $423 \mathrm{~K}$ exhibits strength comparable to those of RT bonding even if the ultrasonic power is less than $50 \%$ of RT bonding. ${ }^{13)}$ Next we did wire bonding at RT and $423 \mathrm{~K}$ by varying the bonding times and examined the shear strength. The shear strength of $\mathrm{Al}$ and $\mathrm{Al}-\mathrm{Ni}$ wire bonds were plotted against their bonding times in 
a)

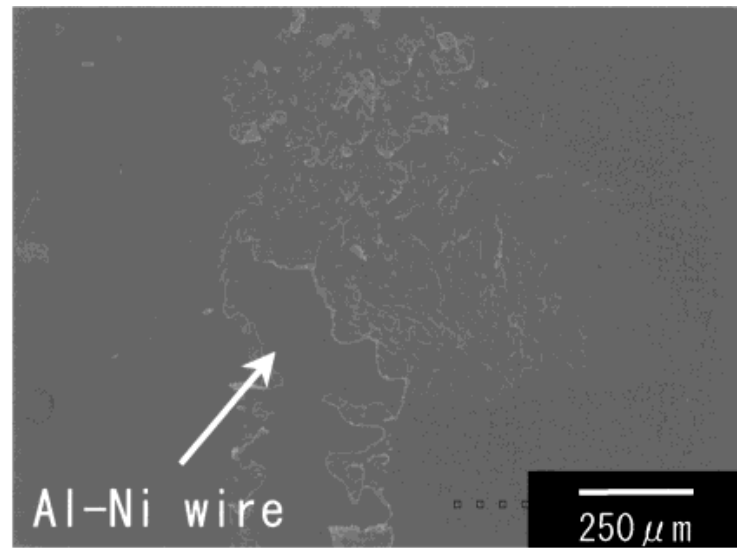

b)

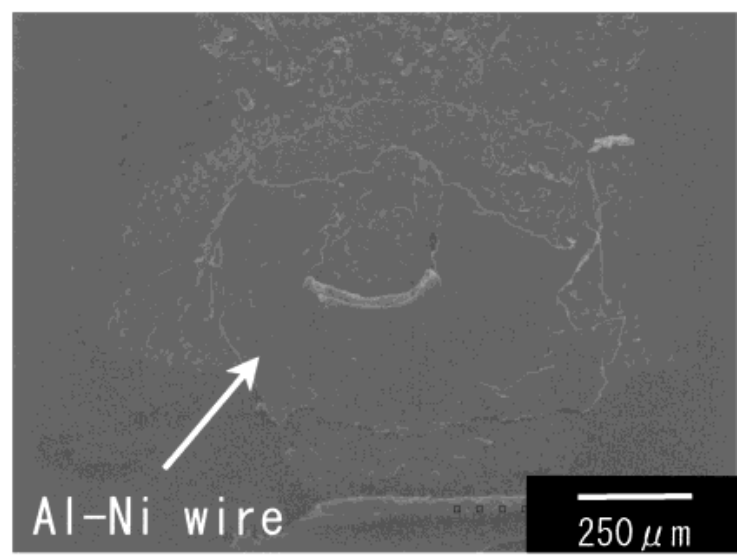

c)

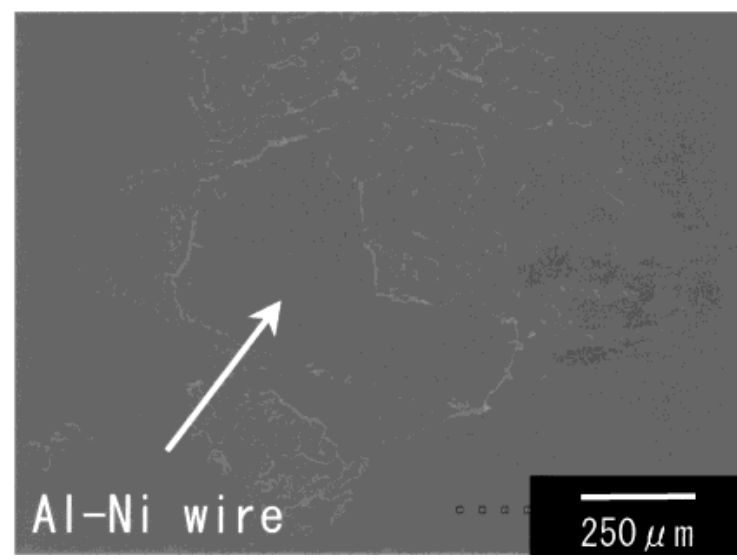

Fig. 10 The fracture surfaces of Al-Ni wire bonds after the shear test. (a) $423 \mathrm{~K}, 10 \mathrm{~ms}$, (b) $423 \mathrm{~K}, 40 \mathrm{~ms}$, (c) RT, $180 \mathrm{~ms}$.

Fig. 9. The shear strength of $\mathrm{Al}$ and $\mathrm{Al}-\mathrm{Ni}$ wire bonds joined at $423 \mathrm{~K}$ increases with bonding time from 10 to $40 \mathrm{~ms}$. The shear strength of $\mathrm{Al}$ and $\mathrm{Al}-\mathrm{Ni}$ wire bonds joined at $423 \mathrm{~K}$ for $40 \mathrm{~ms}$ is comparable to those of $\mathrm{Al}$ and $\mathrm{Al}-\mathrm{Ni}$ wire bonds joined at RT for $180 \mathrm{~ms}$, respectively.

Figure 10 shows the fractured surfaces of Al-Ni wire bonds after the shear test. (a) and (b) correspond to fractured surfaces joined at $423 \mathrm{~K}$ for $10 \mathrm{~ms}$ and $40 \mathrm{~ms}$, respectively. While, (c) corresponds to the fractured surface joined at RT for $180 \mathrm{~ms}$. It can be seen from (a) that the Al-Ni wire bond broke mainly at the bonding interface, because the residual area of Al-Ni wire bond was small as marked by an arrow. In the cases of (b) and (c), similar fractured surfaces can be seen. The Al-Ni wire bonds broke at the Al-Ni wires, because the residual areas of $\mathrm{Al}-\mathrm{Ni}$ wire bonds were very large in both cases, as shown in (b) and (c). These results clearly show that high temperature bonding can reduce the bonding time to less than $1 / 4$ as compared with RT bonding without the occurrence of Si damage. High temperature bonding enhances the deformation of $\mathrm{Al}$ electrodes and $\mathrm{Al}$ wires and breaks the oxides of both, resulting in a increase in the true bonded area, even in a short time range. Hence high temperature bonding using $\mathrm{Al}-\mathrm{Ni}$ wire is considered to be one of the most promising candidates for the mass production of highly reliable large current power modules.

\section{Conclusions}

In order to create a high-strength and high-speed thick Al wire bonding technology, we have investigated high temperature bonding at $423 \mathrm{~K}$ using $\mathrm{Al}-\mathrm{Ni}$ wire. The following results were obtained.

(1) The strength of the wire bonds using Al-Ni wires was found to be higher than those using $\mathrm{Al}$ wires.

(2) Al-Ni wire bonds joined at $423 \mathrm{~K}$ for $40 \mathrm{~ms}$ exhibited high strength, which is comparable to Al-Ni wire bonds joined at RT for $180 \mathrm{~ms}$.

(3) It is possible to substantially reduce the occurrence of $\mathrm{Si}$ damage if high temperature thick $\mathrm{Al}-\mathrm{Ni}$ wire bonding technology is used.

(4) High-temperature, high-speed bonding using Al-Ni wire can be considered as a promising bonding technology for the mass production of low cost power modules.

\section{Acknowledgements}

The authors would like to thank Mr. H. Ookubo of Hitachi Works for his encouragements and discussions.

\section{REFERENCES}

1) J. Kassakian, M. Schiechi and G. Verghese: Principles of Power Electronics, (Addison-Wesley, 1991) Chap. 16.

2) M. Mori, R. Saitou and T. Yatsuo: Proc. 5th ISPSD (1993) p. 287-291.

3) R. Saitou and M. Mori: OHM 81 (1994) 33-37 (in Japanese).

4) Y. Takahashi, T. Koga, H. Kirihara and Y. Seki: Proc. 6th ISPSD(1994) p. 25-28.

5) W. Wu, M. Held, P. Jacob, P. Scacco and A. Birolini: Proc.7th ISPSD (1995) p. 330.

6) J. Onuki,Y. Chonan,T. Komiyama, M. Nihei, R. Saitou, M. Suwa and T. Morita: Jpn. J. Appl. Phys. 40 (2001) 3985-3991.

7) G. Harman: Wire Bonding in Microelectronics, (McGraw-Hill, 1997) 2nd ed. Chap. 4.

8) C. Hager: Lifetime Estimation of Al Wire Bonds Based on Computational Plasticity, (Hartung-Corre, 2000) Chap. 2.

9) J. Onuki and M. Koizumi: Mater. Trans., JIM 37 (1996) 1319-1323.

10) V. H. Winchell and K. O. Berg: IEEE Trans. CHMT Vol. CHMT-1 (1978) 211-219.

11) Tanaka Densi Kogyo: Private communication.

12) W. B. Brown: Advanced Electronic Packaging, (IEEE Press, 1999) pp. 395-396.

13) T. Komiyama, Y. Chonan, J. Onuki, M. Koizumi and T. Shigemura: Jpn. J. Appl. Phys. Accepted for publication.

14) T. B. Massalski: Binary Alloy Phase Diagrams, 2nd ed. (ASM International, 1992) pp. 181-184.

15) J. Onuki, M. Suwa, M. Koizumi and T. Iizuka: IEEE Trans. on CHMT. Vol. CHMT-10 (1987) pp. 242-246. 